\title{
EDUCAÇÃO DE MÃE PARA FILHO: FATORES ASSOCIADOS À MOBILIDADE EDUCACIONAL NO BRASIL*
}

\author{
Flávia Vitor LONGo ${ }^{1}$ \\ Joice Melo Vieira ${ }^{2}$
}

RESUMO: A mobilidade educacional intergeracional ascendente pode ser entendida como a situação em que os filhos superam a escolaridade de seus pais. $\mathrm{O}$ objetivo deste estudo foi identificar quais fatores estão associados a maiores chances de adolescentes de 16 a 19 anos, filhos de mulheres de baixa escolaridade, conseguirem concluir ao menos o ensino fundamental. Apesar de modesta, esta é uma conquista recente no país e ainda ocorre de forma desigual. Os dados utilizados sáo provenientes da Pesquisa Nacional por Amostra de Domicílios (1996 e 2012). Os resultados indicam que adolescentes do sexo feminino, brancos e aqueles com menor número de irmãos possuem maiores chances de mobilidade ascendente. Em 2012, o fato de o adolescente trabalhar também favoreceu a mobilidade educacional ascendente.

Palavras-chave: Mobilidade educacional. Adolescência. Demografia. Regressão.

\section{MOTHER-TO-CHILD EDUCATION: FACTORS ASSOCIATED WITH EDUCATIONAL MOBILITY IN BRAZIL}

ABSTRACT: Upward intergenerational mobility can be understood as the situation in which children overcome the schooling of their parents. The aim of this study was to identify which factors are associated with higher odds of 16 to 19 years old teenagers, children of poorly educated women, being able to complete, at least, primary school. Although modest, this is a recent development in the country and still occurs unevenly. The data used are from Pesquisa Nacional por Amostra de Domicílios (National Survey of Households, 1996 e 2012). The results indicate that adolescent females, whites and those with fewer siblings have greater chances of upward mobility. In 2012, the fact that the teenager was working also favored the upward educational mobility.

Keywords: Educational mobility. Youth. PNAD. Regression.

\footnotetext{
*Este artigo apresenta parte dos resultados do Projeto de Pesquisa de Mestrado: "Tal mãe, tal filho?: uma análise da mobilidade educacional intergeracional no Brasil em 1996 e 2012", desenvolvido no Programa de Pós-Graduação em Demografia do Instituto de Filosofia e Ciências Humanas da Unicamp, financiado pelo Conselho Nacional de Desenvolvimento Científico e Tecnológico (CNPq).

${ }^{1}$ Universidade Estadual de Campinas (UNICAMP), Instituto de Filosofia e Ciências Humanas, Programa de Pós-Graduaçáo em Demografia - Campinas (SP), Brasil. E-mail: flavialongo@nepo.unicamp.br ${ }^{2}$ UNICAMP, Instituto de Filosofia e Ciências Humanas, Departamento de Demografia - Campinas (SP), Brasil. E-mail: jmvieira@nepo.unicamp.br DOI: 10.1590/ES0101-73302017162420
} 


\title{
L'ÉDUCATION DE LA MÈRE À L'ENFANT: FACTEURS ASSOCIÉS À LA MOBILITÉ D'ÉDUCATION AU BRÉSIL
}

\begin{abstract}
RÉSUMÉ: La mobilité d'éducation intergénérationnelle ascendante peut être comprise comme la situation dans laquelle les enfants dépassent la scolarité de leurs parents. L’objectif de cette étude est celui d'identifier les facteurs qui sont associés à une plus grande chance que les adolescents de 16 à 19 , descendants de femmes peu instruites, soient capables d'accomplir au moins l'école primaire. Bien que modeste, c'est un développement récent dans le pays et se produit encore de manière inégale. Les données utilisées proviennent de la " Pesquisa Nacional por Amostra de Domicílios " (Recherche Nationale par Échantillon de Domiciles, 1996 et 2012). Les résultats indiquent que les jeunes filles, les blancs et ceux qui ont moins de frères ont plus de chances de mobilité ascendante. En 2012, le fait que l'adolescent travaille a été aussi favorable à la mobilité d'éducation ascendante.
\end{abstract}

Mots-clés: La mobilité d'éducation. L'adolescence. La PNAD. La régression.

\section{Introdução}

palavra "oportunidade" deriva do latim ob portus, nome dado aos ven-
tos favoráveis que sopravam na direçáo conveniente, auxiliando as em-
barcaçóes a partirem ou a chegarem aos portos de destino. Em termos sociológicos, entende-se que as oportunidades se traduzem no acesso a recursos, tanto públicos quanto particulares, que possibilitam às pessoas conquistarem determinados objetivos (KAZTMAN; FILGUEIRA, 1999). Quando as oportunidades são muito desiguais entre os diversos segmentos sociais, estudos sobre mobilidade social, ocupacional ou educacional podem trazer à luz aspectos da dinâmica que rege essas desigualdades. Atentar para os mecanismos que permitem a mobilidade é identificar em quais direçóes os ventos favoráveis sopram, e quem são aqueles que se beneficiam deles.

Neste estudo, assume-se como mobilidade educacional intergeracional a diferença entre os níveis de escolaridade máxima alcançada por duas geraçóes sucessivas, contrastando a escolaridade de adolescentes com aquela de suas mães. Considerando detidamente os filhos de mulheres de baixa escolaridade, definidas aqui como aquelas que não completaram o ensino fundamental, este estudo visa a mensurar a proporçáo de jovens que conseguiu superar a escolaridade da mãe, ou seja, que obteve mobilidade educacional ascendente. O ponto alto dessa investigação é a avaliação de quais fatores estão associados a maiores chances do adolescente superar a baixa escolaridade materna, bem 
como quais são aqueles que acentuam a tendência de reprodução da condição de baixa escolaridade.

A primeira parte deste artigo é dedicada à revisão da literatura sobre mobilidade educacional intergeracional. Em seguida, na seção metodológica, é apresentada a fonte de dados utilizada - Pesquisa Nacional por Amostra de Domicílios (PNAD) de 1996 e 2012 —, assim como a estratégia analítica, baseada na construção de modelos de regressão logística binária múltipla. A partir da comparação dos resultados obtidos com o conhecimento acumulado na bibliografia nacional e internacional, elabora-se a discussão sobre os achados desta pesquisa e registram-se alguns apontamentos para a agenda de investigação sobre mobilidade educacional intergeracional.

\section{Sobre mobilidade educacional intergeracional}

A importância social da mobilidade educacional ocorre por ser esta uma via necessária, ainda que não suficiente, para a mobilidade ocupacional e socioeconômica. Isso ocorre devido à associação entre grau de escolaridade e tipo de inserção produtiva no mercado de trabalho. O entendimento de que a educação é tida como principal via de ascensão socioeconômica pode ser vinculado a orientaçôes e princípios neoliberais (SHIROMA et al., 2011). Porém, mesmo nos casos em que a mobilidade educacional não se traduz em maiores ganhos salariais, uma populaçáo mais escolarizada favorece o aperfeiçoamento das condiçóes gerais de vida, pois tende a fazer melhor uso da informação, exercer seu poder de crítica e contribuir para a elevação do nível de desenvolvimento e organização da sociedade. Almeida (2007), baseado em dados estatísticos da Pesquisa Social Brasileira que entrevistou 2.363 pessoas em 2002, conclui que os altamente escolarizados são mais críticos à corrupção e ao jeitinho brasileiro, ou ao menos conseguem identificar claramente quando tais comportamentos se manifestam. Além disso, tendem a ser mais tolerantes em relaçáo às escolhas afetivo-sexuais de terceiros, censurar a violaçáo de direitos individuais e defender maior igualitarismo na sociedade. Logo, o aumento da escolaridade média do brasileiro aproximaria o comportamento geral da população ao de países mais desenvolvidos.

A associaçáo entre a escolaridade da máe e a condição de vida dos filhos também pode se refletir no nível de escolaridade que eles alcançam. Glória (2005) recupera essa ideia, indicando a necessidade de se articular saberes interdisciplinares para trabalhar melhor as relaçóes entre escolaridade e família. A combinação de diferentes áreas de conhecimento visa a enriquecer a análise sobre o fenômeno da mobilidade educacional, bem como a fornecer técnicas e abordagens que contornem os problemas que surgem nesse tipo de pesquisa.

Uma das dificuldades encontrada nos estudos sobre mobilidade é descrever e explicar como ocorrem a transmissáo e a superaçáo do status educacional 
entre as geraçóes de uma mesma família. A forma como a mobilidade educacional ocorre depende de fatores macrossociais, tal como a conjuntura político-econômica e a sistematização das redes de ensino escolar ou profissionalizante; e de fatores microssociais, a exemplo das características individuais e da família de origem.

Uma possibilidade de se abordar o problema da transmissão é por meio da teoria da distribuição de capitais social, cultural e econômico (BOURDIEU, 1992; HASENBALG, 2003). Da disponibilidade desses capitais dependeria a inserção das crianças e dos adolescentes na sociedade. Segundo Hasenbalg (2003), as oportunidades de escolarização e a qualidade de vida ao longo da existência dependem, em parte, do grupo doméstico em que as crianças e os adolescentes são socializados. Esses três capitais podem ser encontrados e disponibilizados tanto no plano micro (esfera dos indivíduos e das famílias) quanto no plano macro (políticas de Estado e conjuntura econômica do país). A seguir, buscamos explicar brevemente do que se trata cada um dos capitais mencionados.

\section{Capital social}

Coleman (1988) entende que o capital social se expressa por meio da relação existente entre crianças e adultos com os quais elas convivem. $\mathrm{O}$ tempo e a atenção que os adultos dedicam às crianças compóem parte do capital social que elas podem adquirir. Silva (2003), por sua vez, considera aspectos da estrutura doméstico-familiar - tais como o tipo de chefia (se masculina ou feminina) e o número de filhos presentes - como indicadores da disponibilidade desse capital. No espaço doméstico, o autor indica que é preciso avaliar quantos e quais são os adultos com quem os menores convivem, pois a qualidade das relaçóes também interfere no capital social disponível. Nesse sentido, os vínculos se expandem para além dos laços biológicos.

Quanto ao tipo de família, Astone e McLanahan (1991) defendem que haveria um déficit de capital social nos arranjos monoparentais femininos (mãe com filhos). Independentemente da situação que ocasionou a monoparentalidade — divórcios, separaçóes, viuvez, maternidade na adolescência ou fora de unióes — o estudo indicou que a ausência de um dos pais limita o tempo dedicado à interação com os filhos. Nesse sentido, em tese as famílias nucleares apresentariam melhores condiçóes de se dedicarem à educação e à socialização das crianças (HASENBALG, 2003).

A disponibilidade e a distribuição do capital social nos grupos domésticos estão em parte atreladas à transição demográfica e às mudanças nas estruturas das famílias em função da diminuição expressiva das taxas de fecundidade. Ainda que não existam provas de que há uma relação causal entre o tamanho da família e as oportunidades de escolarização, alguns estudos empíricos encontraram uma 
relação inversa entre a quantidade de irmãos e o acesso de crianças e jovens à escolarização (HASENBALG, 2003; GLÓRIA, 2005). Entre grupos de irmãos numerosos tenderia a ocorrer uma diluiçáo do tempo, dos recursos, da energia e da atenção prestada pelos pais e outros adultos da família aos mais novos (HASENBALG, 2003). No entanto, seria interessante verificar se existe um "número ótimo" de irmãos, pois em famílias nas quais existem dois ou mais filhos, o irmão mais velho pode auxiliar o mais novo em suas tarefas, contribuindo para que ele tenha sucesso nas primeiras etapas escolares. Essa é uma condição da qual os filhos únicos não se beneficiam, embora possam ter todos os recursos familiares destinados exclusivamente para eles. Dessa forma, os irmãos também são fonte de capital social e não apenas competidores pelos mesmos recursos da família, podendo agir como agentes de reforço escolar.

Não obstante o capital social estar associado às características das famílias, vimos que ele não se esgota nas relaçóes de parentesco. Segundo Nan (2005), o capital social está presente também na rede social do indivíduo, constituída a partir dos vínculos estabelecidos com a vizinhança e com as diferentes comunidades das quais participa: agremiaçóes, igrejas, grupo escolar, movimentos sociais, cooperativas etc. Nan (2005) entende que esse capital pode ser mobilizado de forma a aumentar as chances de se atingir um fim específico. Diferentemente do proposto por Kaztman e Filgueira (1999), que avaliam como central a questáo do acesso às oportunidades, aqui a mobilização desse capital pressupóe a capacidade de agência dos indivíduos.

\section{Capital cultural}

Na concepção de Bourdieu (1992), o capital cultural traduz-se em conhecimento apreendido e depende principalmente do acesso à escola e aos livros. Hasenbalg (2003) argumenta que as coortes mais jovens têm se beneficiado da expansão educacional ocorrida no país, além de estarem sendo socializadas por pais e adultos mais escolarizados que os de geraçóes anteriores. Segundo o autor, mesmo em diferentes estratos de renda, houve redução da desigualdade educacional entre os adultos. Hasenbalg (2003) afirma, ainda, que a distribuição do capital cultural também depende do grau de urbanização. Frequentemente a literatura frisa que as áreas urbanas oferecem melhor infraestrutura e oportunidades de escolarização (TERUYA, 2000; HASENBALG, 2003).

A regiâo de residência é um indicador dos aspectos institucionais que influenciam diretamente as oportunidades de escolarização. Residir em espaços com maior oferta de bens públicos dedicados à escolarização, à profissionalização e ao lazer aumentaria a chance de crianças e adolescentes acessá-los e se beneficiarem deles.

O sistema educacional cumpre papel fundamental na promoção do capital cultural como locus de socialização das novas geraçôes. Boudon (1973 
apud SILVA, 2003), porém, já advertia que a expansão desses sistemas não implica no aumento de chances de escolarização. $\mathrm{O}$ acesso à escola não garante a permanência, tampouco a conclusão de determinada etapa do ensino. Conforme veremos, a permanência do aluno no sistema escolar é o desafio imposto aos gestores de políticas educacionais.

\section{Capital econômico}

Por fim, o capital econômico também guarda relação com as chances de mobilidade educacional. Segundo Hasenbalg (2003), a distribuição desse tipo de capital está associada à evolução das taxas de crescimento da economia e da distribuição de renda.

Um argumento presente nessa associação é de que um maior acúmulo de renda pela família permitiria melhor articulação dos demais capitais, pois seria um agente facilitador no acesso aos capitais social e cultural. Para Soares e Collares (2006), a disponibilidade do capital econômico no grupo doméstico-familiar determinaria as decisōes sobre a trajetória estudantil: ou investe-se na formação escolar/profissionalizante; ou ocorre o ingresso prematuro no mercado de trabalho; ou, ainda, recorre-se à combinação dessas duas condiçôes.

Além da distribuição, do acesso e da mobilização desses três capitais, também consideramos as políticas educacionais como um fator que atua sobre as chances de mobilidade educacional.

\section{Políticas educacionais e contextos de escolarização}

Entendemos que o acesso às oportunidades educacionais não depende exclusivamente do indivíduo e/ou das decisóes e dos esforços de sua família. Podemos supor que as políticas voltadas para a ampliação do acesso e da permanência dos estudantes no sistema escolar são mecanismos que contribuem para o aumento da escolaridade. Sendo as políticas educacionais um instrumento do Estado, as mesmas são delineadas de acordo com a conjuntura política do país.

Segundo Dourado (2007), depois da redemocratização, a educação passa a ser vista como direito social inalienável e é partilhada entre os entes da Federação. Em seu artigo, o autor discute a organização e os limites de programas do governo federal destinados à Educaçáo, como o Plano de Desenvolvimento da Escola, o Programa Dinheiro Direto na Escola e o Programa Nacional de Fortalecimento de Conselhos Escolares. O autor entende que a constituição e a trajetória das políticas educacionais no Brasil têm sido marcadas pela descontinuidade e ausência de planejamento de longo prazo. Por essa perspectiva, as açóes tornam-se 
desarticuladas entre si e entre os próprios sistemas de ensino, dificultando o acesso e a permanência no ambiente escolar.

Além do efeito das políticas sobre as chances de mobilidade, consideramos que os diferentes contextos em que ocorreu a escolarização de mães e filhos guardam relaçáo com a mobilidade. Por exemplo, as máes de adolescentes em 1996 provavelmente se encontravam em idade escolar entre as décadas de $1960 \mathrm{e}$ 1970; já aquelas que eram mães de adolescentes em 2012 devem majoritariamente ter vivenciado essa fase da vida entre os anos 1970 e 1980. A própria estrutura de oportunidades a que essas mulheres estiveram expostas em seus anos de infância e adolescência eram diferentes, posto que o contexto político-econômico e mesmo o padrão de formação de família vigente no país passaram por importantes transformaçóes na segunda metade do século XX.

Para melhor compreender a mobilidade educacional intergeracional, recuperamos a seguir os principais achados de trabalhos internacionais e nacionais sobre o tema. O propósito central desta breve revisão foi comparar as semelhanças e diferenças do fenômeno entre países.

\section{Dos trabalhos internacionais sobre mobilidade educacional intergeracional}

Analisando dados da International Adult Literacy Survey (IALS), Pfeffer (2007) questionou o grau de associação existente entre o contexto familiar e as oportunidades educacionais que uma pessoa poderia ter. $\mathrm{O}$ autor comparou os processos de mobilidade educacional em 20 países ${ }^{1}$. Concluiu que essas nações diferem largamente quanto à influência da família e do sistema educacional sobre as chances de mobilidade; e que a predominância de uma economia calcada no setor terciário está associada a um acesso maior às oportunidades de escolarização.

$\mathrm{O}$ autor apontou três elementos que explicariam a relação entre o status educacional de diferentes geraçoos de uma mesma família, aos quais vinculamos os três capitais:

1. a experiência educacional dos pais permite traçar estratégias sobre o percurso escolar de seus filhos - capital social;

2. a disponibilidade de livros e de recursos para aprendizagem, tanto na escola quanto no ambiente doméstico, aumenta as chances de êxito escolar - capital cultural; e

3. havendo múltiplas alternativas, pais e filhos tenderiam a fazer escolhas racionais sobre a formaçáo escolar-profissional, com base nos custos e na utilidade conferida pelas opçôes disponíveis - capital econômico. 
Mare e Chang (2003) buscaram retratar os efeitos da escolaridade dos pais sobre a escolaridade dos filhos, comparando Taiwan e Estados Unidos. Identificaram a influência dos constrangimentos econômicos sobre as decisóes nas trajetórias educacionais: quando ocorre uma forte transformação na economia, mudam as características da força de trabalho - o que leva às diferenças nos status educacionais de pais/mães e filhos. Sob esse aspecto, em comparação com Taiwan, nos Estados Unidos observou-se um efeito menor da escolaridade dos pais sobre a dos filhos, uma vez que as oportunidades econômicas e profissionais nesse país têm um peso maior e balizam as decisóes sobre a formação escolar. Destacam ainda uma diferença cultural importante que impacta a mobilidade: em Taiwan as meninas são destinadas ao casamento, de modo que, em famílias de poucos recursos, a educaçáo delas fica em segundo plano. Assim, os estudos sobre mobilidade na sociedade taiwanesa registram resultados diferenciados segundo o sexo. A principal diferença encontrada na comparaçáo entre EUA e Taiwan foi que, no primeiro, a influência da educação dos pais sobre a mobilidade dos filhos independe do sexo dos pais, do sexo dos filhos e do tamanho da família.

Aproximando-se do contexto brasileiro, Behrman et al. (2000) investigaram a mobilidade educacional na América Latina, com foco nos efeitos das condiçôes macroeconômicas e das políticas educacionais. O trabalho utilizou dados da Organização das Nações Unidas para a Educação, a Ciência e a Cultura (UNESCO) captados entre 1980 e 1996. Para o Brasil, encontraram que, em $1995,27,2 \%$ dos jovens haviam superado a escolaridade de seus pais e suas mães. No mesmo ano, o percentual de jovens bolivianos a superar a escolaridade dos pais foi de $80 \%$ e, dentre os países do Cone Sul, os percentuais de jovens a realizarem a mobilidade educacional ascendente em relação a seus pais foi: $12,5 \%$ na Argentina; 53,1\% no Paraguai; e 70,4\% no Uruguai. Os autores concluem que a segregação espacial, a discriminação racial e a pluralidade dos arranjos familiares restringem as chances de mobilidade.

Abordando especificamente o caso brasileiro, destacamos os trabalhos realizados por Ferreira e Veloso (2003) e Paschoal (2008), aos quais nos deteremos na próxima seção.

\section{Dos trabalhos sobre mobilidade educacional intergeracional no Brasil}

Ferreira e Veloso (2003) ofereceram um amplo panorama sobre a dinâmica educacional intergeracional no Brasil. Os autores utilizaram a PNAD de 1996 e indicaram que o grau de mobilidade difere principalmente entre as cinco grandes regióes do país e segundo as características de raça/cor da população. No estudo, foi considerada a mobilidade em relação à escolaridade da mãe e do pai, pois a PNAD daquele ano contou com um bloco de perguntas sobre mobi- 
lidade social, no qual constavam informaçôes sobre a escolaridade dos pais dos responsáveis pelos domicílios e dos pais de seus cônjuges.

De acordo com os autores, a mobilidade era maior no Sudeste e entre a população que se declarou branca. A persistência do status educacional era maior entre os filhos cujos pais tinham baixa escolaridade, em comparação com aqueles com pais de maior escolaridade.

Ferreira e Veloso (2003) lançaram a hipótese de que as características da mobilidade educacional estariam associadas aos efeitos da comunidade e à restrição de crédito e financiamento, uma vez que esses fatores configuram parte da rede social em que as pessoas estão inseridas. Pode-se deduzir a partir desse estudo que a restrição de acesso aos capitais social e econômico compromete a mobilidade educacional.

O trabalho de Paschoal (2008), por sua vez, adotou uma perspectiva econômica sobre o tema. Seu objetivo foi mensurar esse tipo específico de mobilidade no Brasil também utilizando a PNAD de 1996. A autora explica que os movimentos entre os status educacionais podem ser absolutos ou relativos. Um movimento absoluto ocorre quando todos os indivíduos experimentam os mesmos ganhos ou as mesmas perdas, em relação a um determinado indicador. Um movimento relativo ocorre quando há trocas de posição entre os indivíduos dentro de uma mesma distribuição, sem implicar em mudanças no nível do indicador. Os movimentos absolutos podem não resultar em melhorias nas posiçóes de hierarquia social, mas certamente devem ser desejados pelos gestores públicos. Isso porque esses movimentos representam ganhos coletivos de grande magnitude, que refletiriam, por exemplo, a universalização do acesso e da permanência no sistema educacional.

Paschoal (2008) selecionou a população com idade entre 23 e 69 anos, a fim de garantir a comparação entre a escolaridade de pais e filhos. O limite etário inferior visou a excluir indivíduos que estivessem em idade escolar, seja na educação básica ou universitária. Em seu estudo, observou que a escolaridade da mãe tem maior influência sobre o nível educacional alcançado pelos filhos do que a escolaridade do pai, independentemente do sexo. A diferença de escolaridade de filhos e filhas é menor em relação às mães do que em relação aos pais. Isso ocorre porque as mulheres e as coortes mais jovens em geral tendem a ser mais escolarizadas do que os homens e as pessoas mais velhas. Ademais, as filhas apresentam maior mobilidade educacional do que os filhos.

Segundo a autora, conforme se avança na trajetória escolar a variável raça/ cor aumenta sua importância como elemento explicativo da continuidade dos estudos, sendo que os negros se encontram em desvantagem frente aos brancos. Ribeiro (2003), em seu artigo sobre oportunidades de mobilidade social no Brasil, entre 1973 e 1996, constata que tanto a classe social quanto a cor são fatores relevantes na história das desigualdades brasileiras. Para ele, a principal origem das desigualdades está no legado das injustiças herdadas de uma sociedade rural e escravocrata. 
Diante do quadro exposto, nosso principal objetivo foi identificar quais fatores sociodemográficos estariam associados às chances de superação da escolaridade materna. A seguir, apresentamos a fonte de dados utilizada e nossas escolhas metodológicas.

\section{Metodologia}

Os dados utilizados neste estudo são provenientes da PNAD dos anos de 1996 e 2012, considerando as informaçóes do questionário padrão. A escolha desses dois pontos no tempo visa a captar mudanças promovidas pela Lei de Diretrizes e Bases da Educação Nacional (LDB), de 20 de dezembro de 1996, que estabelece a obrigatoriedade do ensino fundamental e sua universalização.

A PNAD permite recuperar todas as informaçōes sociodemográficas das mães e de seus filhos, desde que eles residam no mesmo domicílio, independentemente da posição que ocupem no arranjo domiciliar. Por outro lado, a partir do questionário padrão, não é possível reconstruir com certeza o vínculo de paternidade, a menos que o pai ou o filho seja apontado como o responsável pelo domicílio.

Neste estudo optamos por considerar adolescentes de 16 a 19 anos, assumindo que, em sua maioria, eles ainda residiriam com a mãe nessa idade, bem como teriam vivido tempo suficiente para ter cumprido o ensino fundamental em fase - caso não tenham interrompido os estudos em algum momento, tampouco tenham sofrido reprovaçôes.

Combinando os dados sobre frequência escolar, grau, curso e série em andamento ou concluídos, criamos uma variável indicadora do nível máximo de escolaridade alcançado pelos adolescentes e por suas mães até o momento da pesquisa. Essa variável assumiu como categorias:

1. Sem instrução a fundamental incompleto;

2. Fundamental completo a médio incompleto;

3. Médio completo a superior incompleto; e

4. Superior completo.

$\mathrm{Na}$ sequência, selecionamos apenas os filhos de mulheres de baixa escolaridade, aquelas com fundamental incompleto ou menos. Então, criamos a variável "mobilidade educacional", que reclassifica os filhos dessas mulheres em duas categorias: aqueles que superaram a escolaridade da mãe, isto é, concluíram pelo menos o ensino fundamental ou mesmo foram além; e aqueles que não superaram suas mães, mantendo o status de baixa escolaridade. 
Para investigar quais variáveis influenciam a dinâmica da mobilidade, optamos pela aplicação de um modelo de regressão logística binária múltipla. Esse tipo de modelagem é empregado quando a variável dependente, aquela que se deseja explicar, é dicotômica. A nossa variável dependente, "mobilidade", possui como categorias: (1) "sim, supera a escolaridade materna"; ou (0) "náo supera a escolaridade materna".

A aplicação da modelagem estatística busca identificar quais fatores aumentam a probabilidade de o adolescente superar a baixa escolaridade de sua mãe. Consideramos como variáveis independentes ou explicativas: sexo, cor e ocupação do adolescente (trabalhava ou não na semana de referência); número de irmãos no domicílio; tipo de família; situação de domicílio urbano ou rural; grande região de residência; renda domiciliar per capita e faixa etária da mãe. Considerando os trabalhos de Hasenbalg (2003) e Pfeffer (2007), listamos no Quadro 1 as variáveis utilizadas na modelagem segundo sua relação com a teoria dos capitais apresentada previamente. Devido à dificuldade de mensurar os capitais, ressaltamos que as mesmas são indicadores aproximados dos capitais social, cultural e econômico. A primeira coluna refere-se à caracterização sociodemográfica de filhos e mães, e as demais, aos indicadores aproximados dos capitais.

A Tabela 1 apresenta a população total de adolescentes com idades entre 16 e 19 anos, a proporção de adolescentes que residem com as mães e daqueles que possuem mães com baixa escolaridade nos dois pontos no tempo em análise.

\section{Resultados}

Os Gráficos 1 e 2 sintetizam a proporção de crianças e adolescentes que estáo inseridos no sistema educacional em qualquer nível (creche, ensino fundamental, médio e superior). Os filhos de mulheres com mais baixa escolaridade são

\section{Quadro 1}

Variáveis indicadoras aproximadas (proxies) dos capitais.

\begin{tabular}{|c|c|c|c|}
\hline Demográficas & Capital social & Capital cultural & Capital econômico \\
\hline Idade do adolescente & Tipo de família & $\begin{array}{l}\text { Escolaridade do } \\
\text { adolescente }\end{array}$ & $\begin{array}{l}\text { Renda domiciliar } \\
\text { per capita }\end{array}$ \\
\hline Sexo do adolescente & $\begin{array}{l}\text { Número de irmãos no } \\
\text { mesmo domicílio }\end{array}$ & Escolaridade materna & \\
\hline \multirow[t]{3}{*}{ Idade da mãe } & $\begin{array}{c}\text { Ocupaçáo do } \\
\text { adolescente }\end{array}$ & $\begin{array}{c}\text { Adolescente frequenta } \\
\text { escola }\end{array}$ & \\
\hline & & $\begin{array}{l}\text { Grande regiáo de } \\
\text { residência }\end{array}$ & \\
\hline & & Área urbana ou rural & \\
\hline
\end{tabular}


os que entram mais tardiamente no sistema escolar, bem como tendem a deixá-lo precocemente. O menor tempo de inserção no sistema educacional formal já sinaliza que eles encontram maior dificuldade de avançar em seus estudos.

De acordo com os Gráficos 1 e 2 também é possível notar que, ao longo do tempo, a permanência passa a ser um problema maior do que o acesso à escola. Ao comparar os dois pontos no tempo, diferentemente de 1996, percebemos que, em 2012, praticamente não houve distinção entre as crianças e os adolescentes na faixa etária entre 7 e 14 anos no que tange ao acesso à escola. A frequência escolar era de praticamente $100 \%$ para todos os grupos. Porém, a partir dos 15 anos, quanto mais baixa a escolaridade da mãe, mais rapidamente declina a proporção de adolescentes inseridos no sistema de ensino. Em relação às idades finais (15-19 anos), em 2012 houve redução na diferença entre os percentuais de adolescentes fora da escola segundo a escolaridade da mãe, em comparação com 1996.

Em 1996, quase 70\% dos filhos de mulheres com pouca ou nenhuma instrução sequer tinham concluído o ensino fundamental (ver Tabela 2), o que significa dizer que apenas cerca de $30 \%$ deles experimentaram mobilidade ascendente. O cenário mudou em 2012 (ver Tabela 3), quando 66\% dos adolescentes superaram a baixa escolaridade de suas máes.

\section{Tabela 1}

Brasil, 1996 e 2012: casos selecionados (números absolutos e percentual).

\begin{tabular}{|c|c|c|c|c|}
\hline Anos & $\begin{array}{l}\text { Descriçáo dos } \\
\text { adolescentes }\end{array}$ & $\begin{array}{l}\text { Amostra } \\
\text { expandida }\end{array}$ & N amostral* & $\begin{array}{c}\text { Percentual da populaçáo } \\
\text { de 16-19 anos } \\
\text { (amostra expandida) }\end{array}$ \\
\hline \multirow{3}{*}{1996} & $\begin{array}{l}\text { População total de } \\
\text { adolescentes } \\
(16-19 \text { anos })\end{array}$ & 13.002 .180 & 28.245 & 100,0 \\
\hline & $\begin{array}{l}\text { População de } 16-19 \text { anos } \\
\text { que reside com a mãe }\end{array}$ & 10.132 .020 & 21.816 & 77,9 \\
\hline & $\begin{array}{l}\text { População de } 16-19 \text { anos } \\
\text { que reside com máe de } \\
\text { baixa escolaridade }\end{array}$ & 7.077 .695 & 14.995 & 54,4 \\
\hline \multirow{3}{*}{2012} & $\begin{array}{l}\text { Populaçáo total de } \\
\text { adolescentes } \\
\text { (16-19 anos) }\end{array}$ & 13.600 .331 & 25.570 & 100,0 \\
\hline & $\begin{array}{l}\text { População de } 16-19 \text { anos } \\
\text { que reside com a mãe }\end{array}$ & 10.367 .750 & 19.293 & 76,2 \\
\hline & $\begin{array}{l}\text { População de } 16-19 \text { anos } \\
\text { que reside com máe de } \\
\text { baixa escolaridade }\end{array}$ & 5.011 .133 & 9.326 & 36,8 \\
\hline
\end{tabular}

Fonte: Pesquisa Nacional por Amostra de Domicílio (IBGE, 1996; 2012).

* $O$ "N amostral" refere-se ao tamanho da amostra, ou seja, ao número exato de casos considerados na pesquisa. 


\section{Gráfico 1}

Brasil, 1996: proporção de filhos com idade entre 0 e 19 anos inseridos no sistema educacional segundo a escolaridade materna (\%).

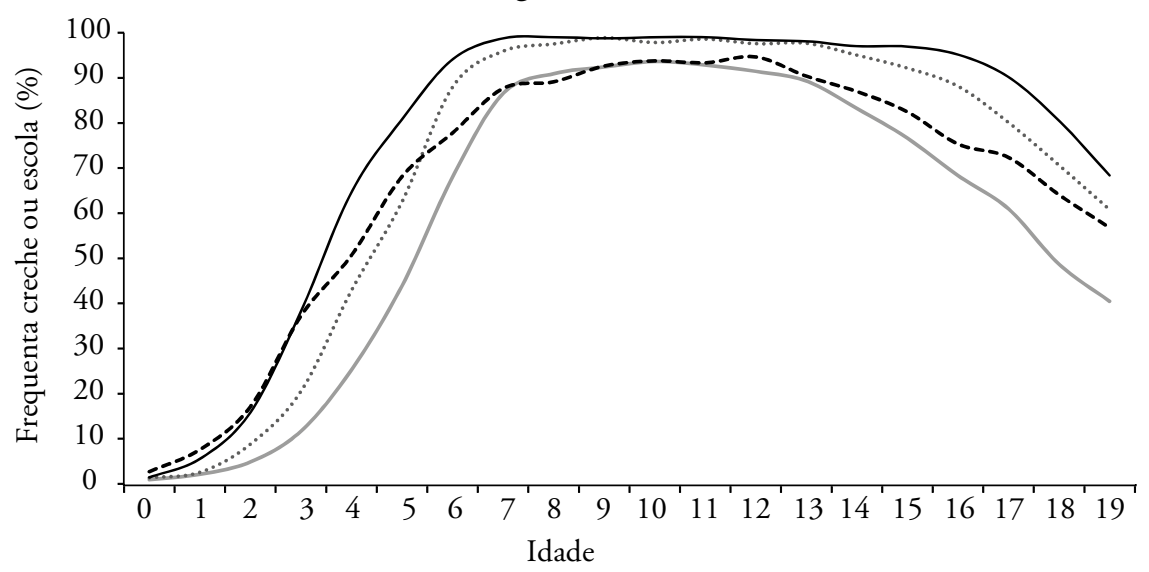

— Filhos de mães sem instrução/ fund. incompleto

..... Filhos de mães com fund. completo/ médio incompleto

— Filhos de mães com médio completo/superior incompleto

--- Filhos de máes com superior completo

Fonte: Pesquisa Nacional por Amostra de Domicilio (IBGE, 1996).

\section{Gráfico 2}

Brasil, 2012: proporçâo de filhos com idade entre 0 e 19 anos inseridos no sistema educacional segundo a escolaridade materna (\%).

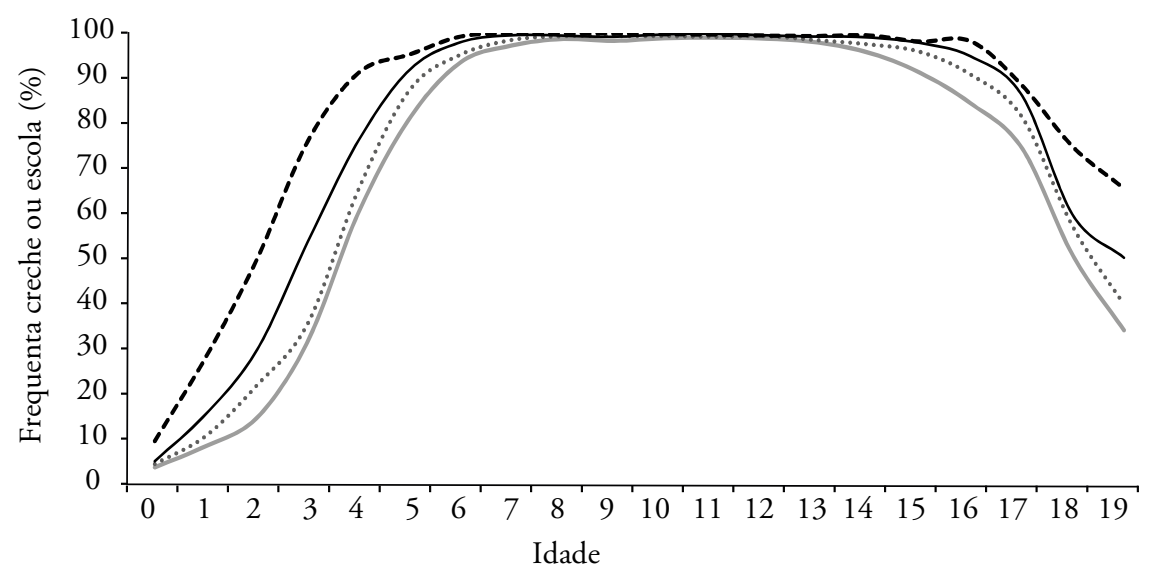

— Filhos de mães sem instrução/ fund. incompleto

Filhos de mães com fund. completo/ médio incompleto

— Filhos de mães com médio completo/superior incompleto

--- Filhos de mães com superior completo

Fonte: Pesquisa Nacional por Amostra de Domicílio (IBGE, 2012). 
A composição do grupo de adolescentes que superou o nível de escolaridade materno sofreu alterações no período em análise. Enquanto em 1996 havia 81,5 meninos para cada 100 meninas entre aqueles que atingiam mobilidade ascendente, em 2012 encontramos 95,5 meninos para cada 100 meninas.

Quanto à cor, destacamos o fato de o país apresentar marcas históricas de segregação de oportunidades, que contribuem para que ocorram trajetórias educacionais diferenciadas entre brancos e não brancos (sobretudo pretos e pardos). Empiricamente, essa diferença pode ser mensurada pela razão de chances (RC): a relação entre a ocorrência de um evento em um grupo e a ocorrência deste mesmo evento em outro grupo. Considerando a distribuição dos adolescentes que

\section{Tabela 2}

Brasil, 1996: distribuição percentual dos adolescentes (16-19 anos) segundo a escolaridade de suas mães e a escolaridade alcançada por eles próprios.

\begin{tabular}{l|c|c|c}
\hline & \multicolumn{3}{|c}{ Escolaridade alcançada pelo filho } \\
\cline { 2 - 4 } & Fundamental incompleto & Fundamental completo & Total \\
\hline $\begin{array}{l}\text { Filhos de mães sem instruçáo } \\
\text { ou fundamental incompleto }\end{array}$ & 67,2 & 32,8 & 100 \\
\hline $\begin{array}{l}\text { Filhos de mães com } \\
\text { fundamental completo } \\
\text { ou mais }\end{array}$ & 26,6 & 73,4 & 100 \\
\hline Total & 56,8 & 43,2 & 100 \\
\hline
\end{tabular}

Fonte: Pesquisa Nacional por Amostra de Domicílio (IBGE, 1996).

Obs.: Ao trabalhar com niveis educacionais não se registra avanços educacionais menores como o aumento de um ou dois anos de estudo em relação à mãe. Por exemplo, se a mãe estudou até o quinto ano e o filho até o sétimo, este filho segue tendo o mesmo status educacional da mãe: fundamental incompleto.

\section{Tabela 3}

Brasil, 2012: distribuição percentual dos adolescentes (16-19 anos) segundo a escolaridade de suas mães e a escolaridade alcançada por eles próprios.

\begin{tabular}{l|c|c|c}
\hline & \multicolumn{3}{|c}{ Escolaridade alcançada pelo filho } \\
\cline { 2 - 4 } & Fundamental incompleto & Fundamental completo & Total \\
\hline $\begin{array}{l}\text { Filhos de mães sem instrução } \\
\text { ou fundamental incompleto }\end{array}$ & 33,8 & 66,2 & 100 \\
\hline $\begin{array}{l}\text { Filhos de mães com } \\
\text { fundamental completo } \\
\text { ou mais }\end{array}$ & 11,8 & 88,2 & 100 \\
\hline Total & 22,6 & 77,4 & 100 \\
\hline
\end{tabular}

Fonte: Pesquisa Nacional por Amostra de Domicílio (IBGE, 2012).

Obs.: Ao trabalhar com niveis educacionais não se registra avanços educacionais menores como o aumento de um ou dois anos de estudo em relação à máe. Por exemplo, se a mãe estudou até o quinto ano e o filho até o sétimo, este filho segue tendo o mesmo status educacional da mãe: fundamental incompleto. 
superaram a escolaridade da mãe e daqueles que não superaram segundo a cor, temos (ver Tabela 4)), é possível calcular as chances de superação de adolescentes brancos e não-brancos. Tais chances são obtidas dividindo-se o número de adolescentes que superaram a escolaridade da mãe pelo número daqueles que náo superaram, considerando em separado os grupos de cor para cada ano. Logo:

$$
\text { número de adolescentes que }
$$

Chance de superação $=\frac{\text { superaram a escolaridade da mãe }}{\text { número de adolescentes que não superaram }}$

Chance de superação ${ }_{\text {brancos 1996 }}=1420458 / 1771582=0,8018$

Chance de superaçáo ${ }_{\text {náo brancos 1996 }}=1014156 / 2871499=0,3532$

Chance de superação $_{\text {brancos 2012 }}=1272728 / 431058=2,9526$

Chance de superação $_{\text {náo brancos } 2012}=2020789 / 1286558=1,5707$

Para comparar as chances de sucesso entre brancos e náo brancos nos dois anos em análise, recorremos à razão de chance $(\mathrm{RC})$ : brancos

$\mathrm{RC}_{\text {ano }}=$ Chance de superação brancos ${ }_{\text {ano }} /$ Chance de superação não

$$
\begin{aligned}
& \mathrm{RC}_{1996}=0,8018 / 0,3532=2,3 \\
& \mathrm{RC}_{2012}=2,9526 / 1,5707=1,9
\end{aligned}
$$

Assim, nota-se que, durante o período analisado, houve uma sutil redução das desigualdades por cor. Em 1996 os brancos tinham 2,3 vezes mais chance de

\section{Tabela 4}

Brasil, 1996 e 2012: número absoluto de adolescentes de 16 a 19 anos, filhos de mulheres sem instrução ou com fundamental incompleto, que superaram e não superaram a baixa escolaridade da mãe segundo a cor do adolescente.

\begin{tabular}{l|c|c|c|c}
\hline & \multicolumn{2}{|c|}{1996} & \multicolumn{2}{c}{2012} \\
\cline { 2 - 5 } & Brancos & Náo brancos & Brancos & Náo brancos \\
\hline $\begin{array}{l}\text { Superou (completou o } \\
\text { Fundamental) }\end{array}$ & 1.420 .458 & 1.014 .156 & 1.272 .728 & 2.020 .789 \\
\hline $\begin{array}{l}\text { Não superou (náo } \\
\text { completou o Fundamental) }\end{array}$ & 1.771 .582 & 2.871 .499 & 431.058 & 1.286 .558 \\
\hline & 3.192 .040 & 3.885 .655 & 1.703 .786 & 3.307 .347 \\
\hline
\end{tabular}

Fonte: Pesquisa Nacional por Amostra de Domicílio (IBGE, 1996; 2012). 
superar a escolaridade da mãe do que os não brancos, enquanto em 2012 a chance de superação dos brancos era 1,9 vezes maior do que aquela dos não brancos.

Tanto em 1996 quanto em 2012, há uma leve sobrerrepresentação dos adolescentes em arranjos monoparentais femininos entre aqueles que não superaram a escolaridade materna (ver Gráfico 3).

A Tabela 5 reporta os resultados obtidos a partir da regressão logística binária múltipla. Os resultados gerados por essa via nem sempre coincidem integralmente com aqueles sugeridos pela análise descritiva ou pelo cálculo da razão de chance considerando um cruzamento simples. Isso ocorre especialmente no que diz respeito aos diferenciais por sexo. Embora a razão de sexo mencionada anteriormente possa sugerir que em 2012 havia maior equilíbrio entre o número de meninos e meninas que superavam a baixa escolaridade materna, quando se controla essa comparação inserindo outras variáveis no modelo, observa-se que os diferenciais por sexo aumentaram ao longo do período. Em 1996, as meninas tinham quase o dobro de chance $(1,9)$ de superar a pouca escolaridade materna, quando comparadas aos meninos. Em 2012, o diferencial segundo o sexo se acentuou ainda mais, sendo que elas apresentaram 2,6 vezes mais chances de mobilidade educacional do que eles.

Nos dois anos analisados, identificamos a variável "renda domiciliar per capita" como sendo aquela que está mais associada com a mobilidade. Em 1996, os adolescentes em domicílios correspondentes aos 25\% mais ricos na distribuição tinham três vezes mais chance de mobilidade em relação aos $25 \%$ mais pobres. Ressalta-se que os quartis de renda domiciliar per capita

\section{Gráfico 3}

Brasil, 1996 e 2012: Distribuição dos casos de mobilidade educacional intergeracional segundo arranjo doméstico (\%).

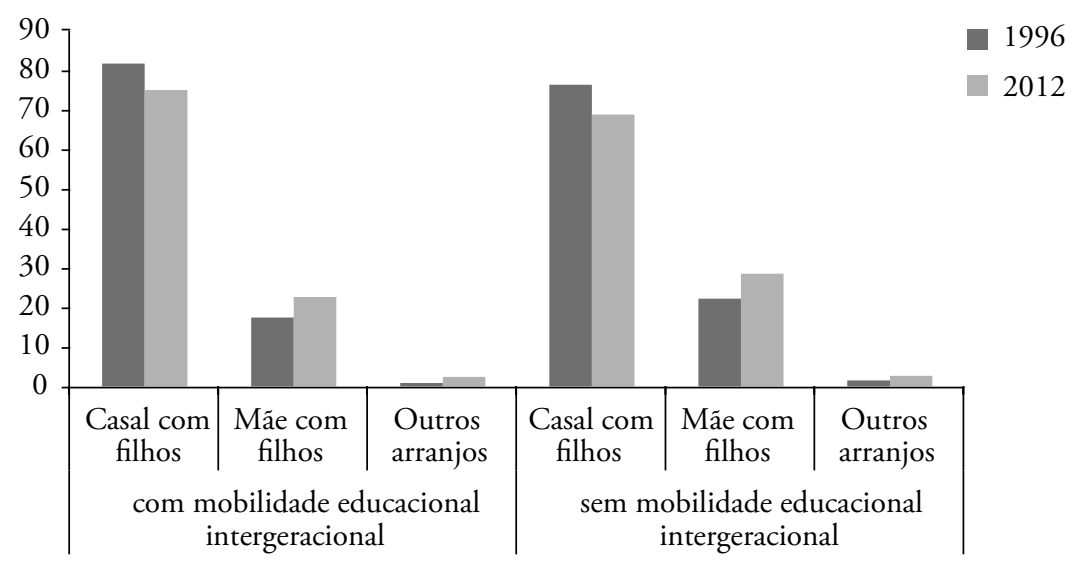

Fonte: Pesquisa Nacional por Amostra de Domicílio (IBGE, 1996; 2012). 


\section{Tabela 5}

Brasil, 1996 e 2012: razóes de chance de mobilidade educacional intergeracional.

\begin{tabular}{|c|c|c|c|c|c|c|c|c|}
\hline \multirow{2}{*}{$\begin{array}{l}\text { Ano } \\
\text { Variável }\end{array}$} & \multicolumn{2}{|c|}{1996} & \multicolumn{2}{|c|}{$\begin{array}{c}\text { Intervalo de } \\
\text { confiança para RC* }\end{array}$} & \multicolumn{2}{|c|}{2012} & \multicolumn{2}{|c|}{$\begin{array}{c}\text { Intervalo de } \\
\text { confiança para RC* }\end{array}$} \\
\hline & Sig**. & $\mathrm{RC}$ & Inferior & Superior & Sig** & $\mathrm{RC}$ & Inferior & Superior \\
\hline \multicolumn{9}{|c|}{ Sexo (referência: masculino) } \\
\hline Feminino & 0 & 1,938 & 1,797 & 2,082 & 0 & 2,610 & 2,370 & 2,874 \\
\hline \multicolumn{9}{|c|}{ Cor (referência: não branco) } \\
\hline Branco & 0 & 1,633 & 1,508 & 1,768 & 0 & 1,449 & 1,303 & 1,611 \\
\hline \multicolumn{9}{|c|}{ Ocupação do filho (referência: ocupado) } \\
\hline Não ocupado & 0,935 & 0,997 & 0,923 & 1,076 & 0 & 0,760 & 0,688 & 0,838 \\
\hline \multicolumn{9}{|c|}{ Ocupação da mãe (referência: ocupada) } \\
\hline Não ocupada & 0,286 & 1,042 & 0,966 & 1,123 & 0,273 & 1,053 & 0,960 & 1,156 \\
\hline $\begin{array}{l}\text { Tipo de família } \\
\text { (referência: casal com } \\
\text { filhos) }\end{array}$ & 0 & & & & 0 & & & \\
\hline Mãe com filhos & 0 & 0,767 & 0,697 & 0,843 & 0 & 0,684 & 0,614 & 0,762 \\
\hline Outros arranjos & 0,008 & 0,639 & 0,459 & 0,889 & 0,049 & 0,748 & 0,560 & 0,999 \\
\hline $\begin{array}{l}\text { Número de filhos no } \\
\text { domicílio (referência: } \\
1 \text { filho) }\end{array}$ & 0 & & & & 0 & & & \\
\hline 2 filhos & 0,065 & 0,877 & 0,763 & 1,008 & 0,342 & 1,070 & 0,931 & 1,230 \\
\hline 3 ou mais filhos & 0 & 0,525 & 0,461 & 0,597 & 0 & 0,674 & 0,591 & 0,770 \\
\hline \multicolumn{9}{|c|}{ Situação de domicílio (referência: rural) } \\
\hline Urbano & 0 & 1,817 & 1,643 & 2,009 & 0,012 & 1,152 & 1,032 & 1,285 \\
\hline $\begin{array}{l}\text { Grande regiāo } \\
\text { (referência: Nordeste) }\end{array}$ & 0 & & & & 0 & & & \\
\hline Norte & 0,245 & 1,118 & 0,926 & 1,350 & 0,336 & 0,928 & 0,798 & 1,080 \\
\hline Sudeste & 0 & 1,639 & 1,484 & 1,810 & 0 & 2,049 & 1,818 & 2,309 \\
\hline Sul & 0 & 1,647 & 1,448 & 1,873 & 0 & 1,367 & 1,165 & 1,605 \\
\hline Centro-Oeste & 0,023 & 1,210 & 1,027 & 1,426 & 0 & 1,765 & 1,425 & 2,185 \\
\hline $\begin{array}{l}\text { Renda domiciliar per } \\
\text { capita (referência: } \\
1^{\circ} \text { quartil) }\end{array}$ & 0 & & & & 0 & & & \\
\hline $2^{\circ}$ quartil & 0 & 1,273 & 1,135 & 1,428 & 0,001 & 1,233 & 1,085 & 1,402 \\
\hline $3^{\circ}$ quartil & 0 & 1,715 & 1,527 & 1,927 & 0,010 & 1,196 & 1,044 & 1,370 \\
\hline $4^{\circ}$ quartil & 0 & 3,135 & 2,788 & 3,524 & 0 & 1,572 & 1,353 & 1,826 \\
\hline \multicolumn{9}{|c|}{ Faixa etária da mãe (45+ anos) } \\
\hline Até 44 anos & 0,130 & 0,944 & 0,875 & 1,017 & 0,010 & 0,883 & 0,803 & 0,971 \\
\hline
\end{tabular}

Fonte: Pesquisa Nacional por Amostra de Domicilio (IBGE, 1996; 2012).

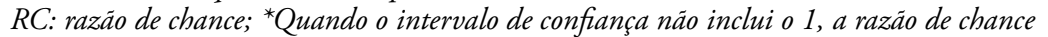
é significativa; ** "Sig" corresponde à significância da estatística Wald. Quando inferior a 0,05, pode-se afirmar que a razão de chance é significativa. 
foram construídos considerando apenas domicílios de adolescentes cujas mães tinham baixa escolaridade. Logo, trata-se aqui de diferenciais de renda considerando um grupo já em situaçáo de alta vulnerabilidade econômica. Em 2012, houve redução das diferenças em relação à renda domiciliar per capita. Ainda assim, os $25 \%$ que dispunham de maior renda apresentavam $57,2 \%$ mais chance de mobilidade do que os mais pobres. Por conseguinte, pode-se afirmar que dispor de maior capital econômico aumenta as chances de mobilidade educacional intergeracional.

Quanto à cor, observamos que os brancos apresentam mais chance de mobilidade, embora essa variável tenha perdido um pouco de sua força explicativa ao longo do período. Em 1996, os brancos tinham 63,3\% mais chance de vir a superar a escolaridade de suas mães do que os não brancos. Em 2012, esse diferencial decresceu, e os brancos passam a apresentar uma chance de mobilidade $44,9 \%$ maior do que os não brancos.

Contrariando as expectativas de que trabalho e escola são concorrentes e inconciliáveis, $\mathrm{o}$ fato de o adolescente trabalhar se mostrou uma variável favorável à mobilidade em 2012. Podemos supor que, em contextos nos quais é mais difícil a garantia dos direitos básicos e os recursos são mais escassos, o trabalho do adolescente aumente as possibilidades de investimento na própria educação.

Outros indicadores do capital social tomaram em conta as características das famílias. Ter um irmão no mesmo domicílio (categoria "2 filhos" na Tabela 5) não se mostrou significativo para alterar as chances de mobilidade educacional intergeracional. Contudo, a presença de dois ou mais irmãos (categoria "3 ou mais filhos" no domicílio), em comparação a não ter irmãos, reduz em aproximadamente $47,5 \%$ a chance de superar a baixa escolaridade da máe em 1996, e em 32,6\% em 2012.

Em 1996, estar em um arranjo do tipo "mãe com filhos" diminuía em $23,3 \%$ as chances de superar a escolaridade materna em relação aos adolescentes em lares cuja configuração é a de casal com filhos. A situação não se altera em 2012, posto que os adolescentes em lares monoparentais seguem apresentando $31,6 \%$ menos chance de mobilidade.

De acordo com os dados aqui analisados, ter mãe inserida na força de trabalho ocupada não afeta significativamente as chances de mobilidade educacional dos jovens. Já a idade da mãe só se mostrou relevante em 2012, quando os filhos de mulheres de até 44 anos tinham menos chance de mobilidade do que os filhos das mulheres com idade igual ou superior a 45 anos.

Por fim, é digno de nota que as desigualdades regionais também se fazem presentes no que diz respeito à mobilidade educacional tal como aqui definida, sendo que os adolescentes residentes em áreas urbanas e no Sudeste do país são mais propensos a superar a baixa escolaridade da máe. 


\section{Considerações finais}

A universalização do acesso ao ensino fundamental foi uma das maiores conquistas da educação brasileira nas últimas décadas. Contudo, quando observamos o grupo de adolescentes cujas mães têm pouca ou nenhuma escolaridade, merece atenção pública o fato de que uma parcela significativa deles ainda não consegue concluir o ensino fundamental na idade esperada: cerca de 4,6 milhóes de adolescentes em 1996 e 1,7 milhôes em 2012. O momento pós-universalização guarda desafios à espera de novas soluções. É preciso redobrar a atenção aos adolescentes que seguem sem instrução ou com ensino fundamental incompleto e em defasagem idade-série. Nesse contexto, a reprodução da baixa escolaridade da mãe atesta que o direito à educação básica ainda não está sendo tão amplamente respeitado como deveria.

Os principais achados deste estudo corroboram os resultados de pesquisas anteriores (FERREIRA; VELOSO, 2003; PASCHOAL, 2008). Eles atestam que desigualdades regionais ainda persistem ao longo do tempo, bem como os não brancos e os adolescentes do sexo masculino apresentam menores chances de mobilidade. A política pública deve desenvolver estratégias específicas de retenção e estímulo à escolarização de meninos e não brancos, se assume como compromisso a redução das desigualdades. Esse também é o perfil de adolescentes em situação de maior vulnerabilidade social e mais expostos às situaçóes de violência, criminalidade e marginalidade (VIEIRA, 2011). Os desafios enfrentados, sobretudo, pelos rapazes não brancos estão interconectados e a esperança de alívio ou solução do problema passa necessariamente pela inclusão educacional.

Os resultados deste estudo mostram que houve melhora do nível educacional da população adolescente e que aumentou o número de jovens que superaram a escolaridade materna. Mas ainda é preciso aumentar a taxa de sucesso na conclusão desse nível do ensino. Políticas de expansão do ensino médio dependem do fluxo de saída do ensino fundamental, obviamente. Logo, o seu êxito está atrelado às chances dos estudantes estarem aptos a cursarem etapas mais avançadas do sistema escolar, independente dos constrangimentos que sofram pelas suas características individuais e de origem familiar. Para tanto, continua sendo uma tarefa pendente eliminar desigualdades nos anos iniciais de escolarização.

\section{Notas}

1. Os países considerados foram: Alemanha, Bélgica, Canadá, Chile, Dinamarca, Eslovênia, Estados Unidos, Finlândia, Grã-Bretanha, Hungria, Holanda, Irlanda, Itália, Irlanda do Norte, Noruega, Nova Zelândia, Polônia, República Tcheca, Suécia e Suíça. 


\section{Referências}

ALMEIDA, C.A. A cabeça do brasileiro. Rio de Janeiro: Record, 2007.

ASTONE, N.M.; MCLANAHAN, S.S. Family structure, parental practices and high school completion. American Sociological Review, Washington, v. 56, n. 3, p. 309-320, 1991.

BEHRMAN, J.; BIRDSALL, N.; SZÉKELY, M. Intergenerational mobility in Latin America: deeper markets and better schools make a difference. In: BIRDSALL, N.; GRAHAM, C. New markets, new opportunities? Economic and Social Mobility in a Changing World. Washington, D.C.: Brookings Institution, 2000. p. 135-167.

BOURDIEU, P. A reprodução. Rio de Janeiro: Francisco Alves, 1992.

COLEMAN, J.S. Social capital in the creation of human capital. American Journal of Sociology, v. 84, p. 95-120, 1988.

DOURADO, L.F. Políticas e gestão da educação básica no Brasil: limites e perspectivas. Educação e Sociedade, Campinas, v. 28, p. 921-946, 2007.

FERREIRA, S.G.; VELOSO, F.A. Mobilidade Intergeracional de Educação no Brasil. Pesquisa e Planejamento Econômico, v. 33, n. 3, p. 481-513, 2003.

GLÓRIA, D.M.A. Relação entre escolaridade e diferenças constitutivas das fratrias. Paidéia, v. 15, n. 30, p. 31-42, 2005.

HASENBALG, C. A transição da escola ao mercado de trabalho. In: HASENBALG, C.; SILVA, N.V. Origens e destinos: desigualdades sociais a longo da vida. Rio de Janeiro: Topbooks, 2003. p. 147-172.

INSTITUTO BRASILEIRO DE GEOGRAFIA E ESTATÍSTICA - IBGE. Pesquisa Nacional por Amostra de Domicílio. Rio de Janeiro: CDDI/IBGE, 1996.

. Pesquisa Nacional por Amostra de Domicílio. Rio de Janeiro: CDDI/IBGE, 2012.

KAZTMAN, R.; FILGUEIRA, C. Oficina de Montevideo, Consideraciones iniciales y estructura de oportunidades. In: COMISIÓN ECONÓMICA PARA AMÉRICA LATINA Y EL CARIBE (CEPAL). Marco conceptual sobre activos, vulnerabilidad y estructura de oportunidades. Montevideo, 1999. p. 7-18.

MARE, R.D.; CHANG, H.C. Family attainment norms and educational stratification: the effects of parents' school transitions. Online Working Papers Series, Los Angeles, nov. 2003.

NAN, L. A network theory of social capital. Duke University, 2005. Disponível em: <http:// pro-classic.com/ethnicgv/SN/SC/paper-final-041605.pdf >. Acesso em: 26 jan. 2016.

PASCHOAL, I.P. Mobilidade intergeracional de educação no Brasil. 76f. Dissertação (Mestrado) - Faculdade de Economia, Administração e Contabilidade de Ribeirão Preto. Universidade de São Paulo, Ribeirão Preto, 2008.

PFEFFER, F.T. Intergenerational educational mobility in comparative perspective: persistent inequality in educational attainment and its institutional context. University of Wisconsin-Madison, 2007. Disponível em: <https:/www.ssc.wisc.edu/cde/cdewp/ 2007-09.pdf>. Acesso em: 26 jan. 2016. 
RIBEIRO, C.A.C. Estrutura de classes, condiçôes de vida e oportunidades de mobilidade social no Brasil. In: HASENBALG, C.; SILVA, N.V. Origens e destinos: desigualdades sociais ao longo da vida. Rio de Janeiro: Topbooks, 2003. p. 381-430.

SHIROMA, E.O.; MORAES, M.C.M.; EVANGELISTA, O. Politica Educacional. Rio de Janeiro: Lamparina, 2011.

SILVA, N.V. Expansão escolar e estratificação educacional no Brasil. In: HASENBALG, C.; SILVA, N.V. Origens e destinos: desigualdades sociais ao longo da vida. Rio de Janeiro: Topbooks, 2003. p. 105-146.

SOARES, J.F.; COLLARES, A.C.M. Recursos familiares e o desempenho cognitivo dos alunos do ensino básico brasileiro. DADOS - Revista de Ciências Sociais, Rio de Janeiro, v. 49, n. 3, p. 415-481, 2006.

TERUYA, M.T. A família na historiografia brasileira: bases e perspectivas de análise. In: ENCONTRO NACIONAL DE ESTUDOS POPULACIONAIS, 12., 2000, Caxambu-MG. Anais... Belo Horizonte: ABEP, 2000.

VIEIRA, J.M. Demografia da juventude e direitos: adolescentes em conflito com a lei no Brasil. In: PIZARRO, J.M. Colección de Ensayos Población y Derechos en América Latina. Rio de Janeiro: ALAP Editor, 2011. p. 15-44.

Recebido em 12 de abril de 2016.

Aprovado em 23 de março de 2017. 